\title{
Influence of the Odour of a Honeybee Colony's Food Stores on the Behaviour of its Foragers
}

WHEN a successful honeybee forager makes a food communication dance, potential recruits learn the odour of the food source both from the odour adhering to the dancer's body and from the odour of the nectar the dancer regurgitates to them; the latter is the more important when forage is distant from the hive. Conditioned foragers can be induced to revisit their food source by being touched by, or receiving food from, a companion that has just returned from the source but not danced, although contact with a dancing bee is more effective ${ }^{1,2}$. Bumblebees have nothing equivalent to the dance language of the honeybee, but the odour of the food stores of a Bombus lucorum colony can influence the choice of flower species visited by its foragers ${ }^{3}$, and it seemed possible that honeybee colonies might have a similar primitive form of communication.

Two small honeybee colonies $(A$ and $B$ ) were put into separate nylon screen cages $(3 \times 3 \times 2 \mathrm{~m}$ high) on a lawn and each trained to collect sugar syrup from three gravity feeders of $300 \mathrm{ml}$. eapacity; the positions of the feeders on the lawn inside the cages were changed every few hours. The syrup in each feeder was scented with five drops of either benzyl acetate (colony $A$ ) or methyl heptanone (colony $B$ ) previously diluted in liquid paraffin (1 part scent : 19 parts liquid paraffin). The feeders were refilled when necessary.

On the evening of May 28, after the colonies had foraged for 5 days and each had collected about 51 . of syrup, the feeders were removed; next morning the cages and hives were moved elsewhere on the lawn, and each hive was put against the middle of a side wall and facing the centre of its cage. Petri dishes containing a drop of either benzyl acetate or methyl heptanone were arranged in a $4 \times 4$ latin square on the floor of the cage and during the next $30 \mathrm{~min}$ the bees that hovered over or landed on each were counted. These dishes were then removed and the feeders returned; many of the bees that collected syrup from the feeders during the remainder of May 28 were given white paint marks. That evening all the combs, but not the adult bees, of colonies $A$ and $B$ were exchanged so that each had the food stores, and accompanying odour, collected by the other; the cages and colonies were then moved to new sites on the lawn as before, and next morning (May 29) a latin square of dishes of the two odours, one the training odour and the other the food store odour, was again provided.

During the first $10 \mathrm{~min}$ of observation (see Table 1) bees from colonies $A$ and $B$ made relatively more visits to dishes with the odour of their current introduced food stores than they made to the same odour the previous day $(P<0.02$ for each comparison); this difference was also evident for colony $A$ during the first $30 \mathrm{~min}$ of observation $(P<0 \cdot 05)$. By the second $30 \mathrm{~min}$ period, the proportion of visits to the different odours differed from that during the first 10 min of observation (colony $B: P<0 \cdot 001$ ) and was similar to that of the previous day. The mean number of bees of both colonies visiting the odour, other than the one to which they had been trained, was 14 per

Table 1. NUMRER OF TIMES BEES LANDED OR HOVERED AT PFTRI DISHES

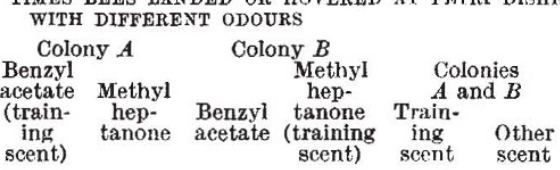

Mlay 28
30 min control
period
May 29
First 10 min period
First 30 min period
Second 30 min
period

163

18

63 114
37

27

30

$$
21
$$

190

24
41

$$
12
$$

353

68
256

256

309 cent on May 28 and $35,17,14,13,11$ and 12 per cent during the six consecutive 10 min periods on May 29.

During the control period on May 28, bees alighted on 18 per cent of the visits to dishes with their particular training odours but on only 3 per cent of the visits to the other dishes $(P<0.01)$. The number of landings at the dishes without the training scent, however, increased to 16 per cent during the first 30 min of observation next day $(P<0.05)$.

On May 29 the dishes were visited by 122 marked bees and 551 unmarked bees, 84 per cent and 83 per cent of which went to their training scent; hence, there is no indication that conditioned foragers behaved differently to the unmarked bees, some of which might have just begun to seek forage.

Another experiment with different colonies was similar except that, instead of exchanging the combs of the two colonies, drops of the training scent of the reciprocal colony were distributed along the wooden tops of the comb frames of each. The presence of the strange odour made no apparent difference to the behaviour of the foragers; 18 per cent of the visits during the control period, 17 per cent during the first $30 \mathrm{~min}$ and 17 per cent during the entire $90 \mathrm{~min}$ of observation the next day, were to the strange odour.

The difference between these two experiments, however, was not only that the introduced scent was present in the food stores in the first but not in the second, but also that throughout the second experiment the colonies' food stores still had the odour of their own training scent.

Foragers can be induced to visit a food source at times other than those to which they have been trained by putting some of its odour into their hive. The results described here show, however, that a strange odour in the hive is not enough to induce foragers to search for it, but does so when it is in the colony's food stores. Hence the extensive transfer of food among the adult members of a honeybee colony must influence the foragers' choice of crop, even when they are conditioned to other food sources and the food is not being transferred during the process of direct crop communication by successful foragers.

This primitive method of communication could help explain the success that has been reported in "directing" bees to crops by feeding their colonies with syrup in which the flowers of the crop have been immersed; also, the waning of the response shown to the odour in the food stores could help explain why "directed" bees soon cease to visit crops from which they get nothing ${ }^{2,5}$.

Rothamsted Experimental Station,

J. B. FREE

Harpenden, Hertfordshire.

Received March 28, 1969.

' Frisch, K. von, Experientia, 2, 397 (1946).

${ }^{2}$ Frisch, K. von, Tanzsprache und Orientierung der Bienen (Springer-Verlag, Berlin, 1965).

${ }^{3}$ Free, J. B., J. Anim. Ecol. (in the press).

4 Ribbands, C. R., Proc. Roy. Ent. Soc. Lond., A, 29, 10 (1954).

${ }^{5}$ Free, J. B., Bee World, 39, 221 (1958).

\section{Song Asynchrony in Neighbouring Bird Species}

ACrually or potentially competing species exhibit "displacement patterns", where various resources such as space, food or light are divided with little or no overlap. We wish to add to this list "broadcasting time", the time available to territorial birds to advertise their assets, for wo have found that the two commonest bird species in California chaparral sing largely out of phase with each other.

On three mornings in March 1968 we recorded the number of songs per min of territorial male birds of eight species. Particular attention was paid to the two commonest species, wrentit (Chamaea fuscata) and Bewick wren 